\title{
Radiation-corrective gas temperature measurement in a circular channel
}

\author{
C. S. Kim, S. D. Hong \& Y. W. Kim \\ Hydrogen Production Reactor Technology Development Division, Korea \\ Atomic Energy Research Institute, Korea
}

\begin{abstract}
Gas temperature measurement by a probe-type thermometer has a large bias because of the thermal radiation effect on the measured surface. In the gas flow, the convective heat transfer coefficient on the thermocouple surface is not large enough to neglect the thermal radiation effect from the sheath tube. Therefore, the measured temperature is determined from the energy balance between the convective heat transfer and the radiation heat transfer on the sheath tube. Korea Atomic Energy Research Institute has tested the methodology to correct the thermal radiation effect for the gas temperature measurement. The methodology is the usage of a couple of thermocouples with unequal diameters called the Reduced Radiation Error (RRE) method. The RRE value is defined as the ratio of the temperature difference between the true gas temperature and the measured temperature from large diameter thermocouple over the measured temperature difference between the thermocouples with the small and large diameters. The RRE value is calculated from the convective heat transfer coefficients and the radiation heat transfer coefficient between two thermocouples. The experimental results with two thermocouples of unequal diameters of $1 / 8$ inch and $1 / 16$ inch showed that the RRE method would have good applicability to the gas temperature measurement in the high temperature and mass flux condition under negligible conditions with the conductive dissipation through the sheath tubes.

Keywords: internal gas flow, gas temperature measurement, radiation bias, Reduced Radiation Error (RRE).
\end{abstract}




\section{Introduction}

When a thermocouple is placed in a gas-flow stream, the measured temperature has two bias sources including the thermal radiation [1] between the sheath tube of the thermocouple between the tube wall and the conduction [2] through the sheath tube as shown in Figure 1.

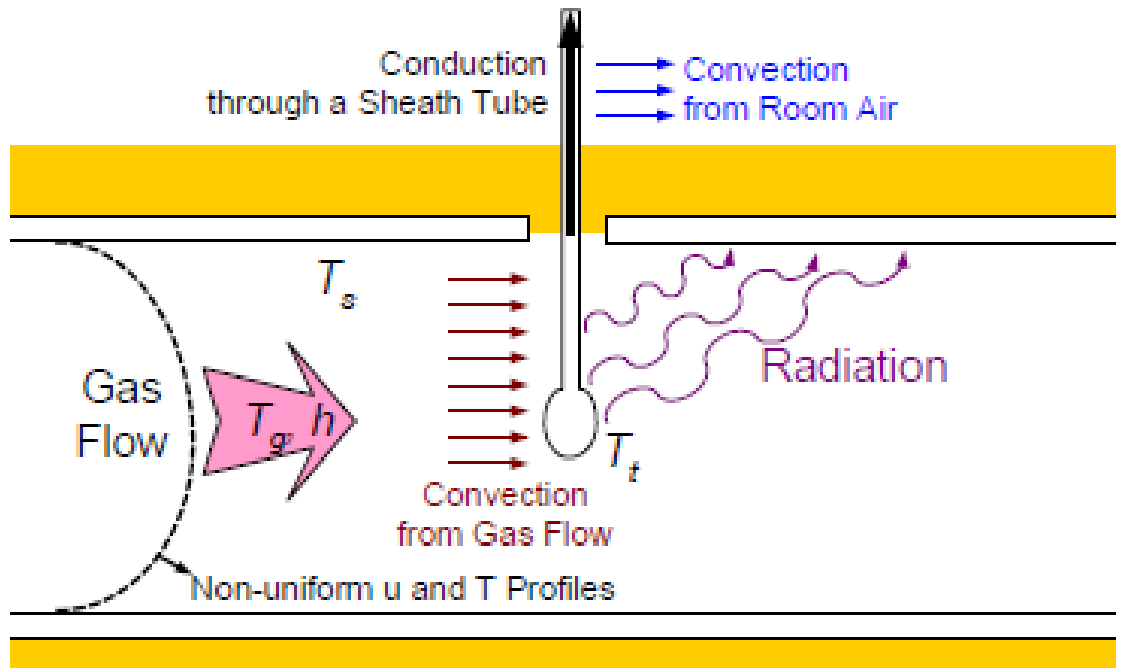

Figure 1: Sources of bias error in gas temperature measurement.

The thermal dissipation effect of the conduction heat transfer can be minimized by the extended isothermal region and thermal insulation of the sheath tube. But the radiation effect is inherent due to the difficulty of the low emissivity control in the high temperature region. Since the high temperature condition results in a large radiation effect, the radiation bias error must be corrected at the hot gas temperature measurement. The effect is dependent on the various factors including the emissivity, convective heat transfer coefficient, and its effective radiation surroundings temperature. Especially, we have difficulty in qualifying the effective surrounding temperature has difficulty, because it is impossible to measure the inner surface temperature distribution of the tube.

Therefore, several investigators have suggested various probe methods for correcting radiation error. The methods are divided into two categories including the minimization of the radiation effect and the radiation-correction through the measured temperature difference between two probes.

The radiation guide tube and the suction pyrometer [3] were suggested to minimize the radiation heat transfer effect from the thermocouple surface. The radiation guide tube is to decrease the difference between the thermocouple temperature and the effective radiation surroundings temperature. The suction pyrometer using the suction gas flow is to maximize the convective heat transfer coefficient for neglecting the radiation bias effect. In the high pressure and 
temperature system, the thermocouple must have a sheath tube with a suitable diameter for the operation temperature. Therefore the radiation protection tube causes the slow response time. In the case of the suction pyrometer, the suction gas flow disturbs the thermo-hydraulic conditions at the closed loop. It is also difficult to install the suction system in the high pressure and high temperature condition.

The measured temperature from two probes is not equal to each other because of the difference between the energy balance conditions of the thermocouples. Two thermocouples with unequal diameters [4] result in the difference between the convective heat transfer coefficients on the probe surface. Two thermocouples with unequal emissivity values [5] cause the difference between the radiation heat transfer coefficients on the probe surface. The emissivity difference is not stably maintained in the high temperature region. Also the qualification of the radiation properties between the thermocouple and their surroundings is necessary to correct the radiation effect. But two thermocouples with unequal diameter are simpler than any other method. Being unnecessary to qualify the effective radiation surroundings temperature is the greatest advantage of this method.

\section{Reduced radiation error}

In the previous section, the radiation from the sheath tube results in an inherent bias error for the gas temperature measurement. If it is assumed that the energy dissipation through the sheath tube, the measured temperature by a probe is determined from the energy balance between the convective heat transfer and thermal radiation on the sheath tube surface as the following equation.

$$
\mathrm{h}_{\mathrm{t}}\left(\mathrm{T}_{\mathrm{g}}-\mathrm{T}_{\mathrm{t}}\right)=\varepsilon \sigma\left(\mathrm{T}_{\mathrm{t}}^{4}-\mathrm{T}_{\mathrm{S}}^{4}\right)
$$

The effective radiation surroundings temperature must be estimated to predict the true gas temperature, when a singular probe is used to measure the gas temperature. If the surface area of the thermocouple end is much smaller than the surrounding area, the effective surrounding temperature will be independent of the diameter of the sheath tube at the same environment. Since unequal diameters of two thermocouples result in the difference between their convective heat transfer coefficients, two thermocouples indicate each other's difference in the case of a large difference between gas temperature and their effective radiation surroundings temperature. The following two energy balance equations are obtained from equation (1) at both two thermocouples.

$$
\begin{aligned}
& \mathrm{h}_{1}\left(\mathrm{~T}_{\mathrm{g}}-\mathrm{T}_{1}\right)=\varepsilon \sigma\left(\mathrm{T}_{1}^{4}-\mathrm{T}_{\mathrm{S}}^{4}\right) \\
& \mathrm{h}_{2}\left(\mathrm{~T}_{\mathrm{g}}-\mathrm{T}_{2}\right)=\varepsilon \sigma\left(\mathrm{T}_{2}^{4}-\mathrm{T}_{\mathrm{S}}^{4}\right)
\end{aligned}
$$

where the subscripts 1 and 2 denote the small diameter and the large diameter, respectively. The convective heat transfer coefficient correlation was referenced 
(Whitaker [6]). The correlation was developed on the spherical surface in the external convective flow.

$$
\mathrm{Nu}_{\mathrm{D}}=\frac{\mathrm{h}_{\mathrm{t}} \mathrm{D}_{\mathrm{t}}}{\mathrm{k}}=2+\left(0.4 \operatorname{Re}_{\mathrm{D}}^{0.5}+0.06 \operatorname{Re}_{\mathrm{D}}^{0.667}\right) \operatorname{Pr}^{0.4}\left(\frac{\mu}{\mu_{\mathrm{s}}}\right)^{0.25}
$$

In equations (2) and (3), there are two unknown variables which are a true gas temperature $\mathrm{T}_{\mathrm{g}}$ and the effective radiation surroundings temperature $\mathrm{T}_{\mathrm{S}}$. From the equations (2) and (3), the reduced radiation error (RRE) was defined by the ratio of the radiation error of the large diameter thermocouple to the temperature difference between two thermocouples as the following equations [4].

$$
\mathrm{RRE}=\frac{\mathrm{T}_{\mathrm{g}}-\mathrm{T}_{2}}{\mathrm{~T}_{1}-\mathrm{T}_{2}}=\frac{\epsilon \sigma\left(\mathrm{T}_{1}^{2}+\mathrm{T}_{2}^{2}\right)\left(\mathrm{T}_{1}-\mathrm{T}_{2}\right)+\mathrm{h}_{1}}{\mathrm{~h}_{1}-\mathrm{h}_{2}}
$$

Therefore, the measured temperature difference between two thermocouples makes it possible to correct the radiation error without estimation on the effective radiation surroundings temperature of the thermocouples. At Korea Atomic Energy Research Institute (KAERI), Kim et al. [7, 8] are developing the temperature measurement methodology and device to correct the radiation bias effect for gas temperature measurement at a very high temperature condition as Figure 2. In this study, the applicability of two thermocouples with unequal diameters is experimentally evaluated to the high temperature gas flow in a circular tube.

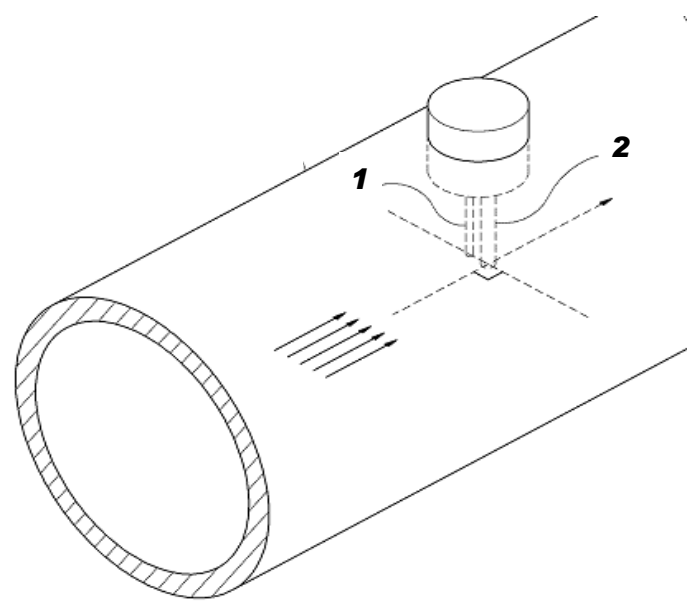

Figure 2: Radiation-correction temperature sensor [6]: 1 (small diameter) 2 (large diameter) 


\section{Experimental setup}

In this study, Kim et al.'s [9] small-scale gas loop was operated to obtain high temperature and large mass flow rate conditions. The loop was composed of a gas-bearing circulator, an inconel 625 pre-heater, a high temperature $\mathrm{C} / \mathrm{C}$ composite heater (main heater), a water-cooled printed circuit heat exchanger, a water-cooled shell-tube heat exchanger, and others as shown in Figure 3. Its working fluid is nitrogen. The gas loop was designed to withstand the maximum temperature of $1000^{\circ} \mathrm{C}$, the maximum pressure of $6.0 \mathrm{MPa}$, and to operate at a maximum mass velocity of $2.0 \mathrm{~kg} / \mathrm{min}$. The nitrogen temperature is controlled by adjusting the power to the heaters using direct voltage controllers. The primary mass flow rate to the gas heating systems controlled by the circulator inverter and the bypass flow control valve. The accumulator maintains the nitrogen loop at a constant pressure. A nitrogen purifier removed oxygen and humidity in the working fluid to prevent the $\mathrm{C} / \mathrm{C}$ composite oxidation in the main heater.

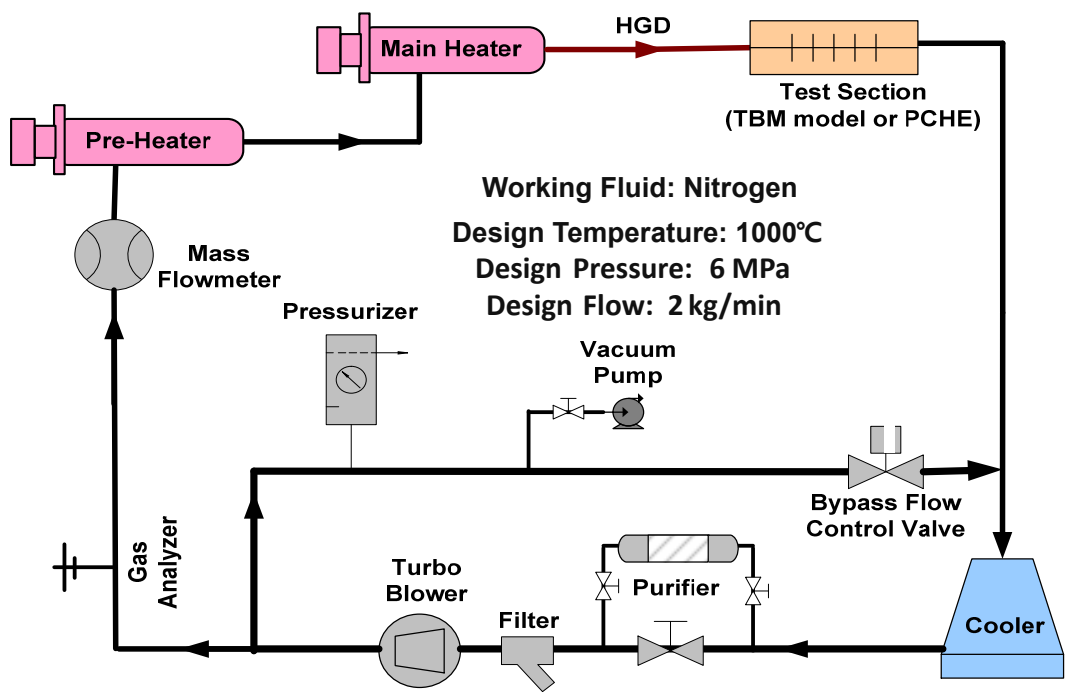

Figure 3: Experimental loop for high-pressure and high-temperature conditions.

A couple of K-type thermocouples with unequal diameters were installed at the inlet of the printed circuit heat exchanger as shown Figure 4. The ground junction thermocouples were selected to dodge the slow response time of the thermocouples. The pipe diameter and pressure design level were 0.5 inch and SCH80, respectively. The combination of $1 / 8$ inch and $1 / 16$ inch was selected for 
stable usage above $800^{\circ} \mathrm{C}$ without thermocouple failure. The sheath tube material is Alloy 600. The gap between two thermocouples was maintained as about 1 2 $\mathrm{mm}$. The gap size was suit to avoid the cross interaction between the thermal boundary layers on the sheath tubes and neglect the gas temperature gradient. The outer surface of the pipe and the sheath tubes were never thermally insulated for the safe operation at high-pressure and high-temperature conditions.

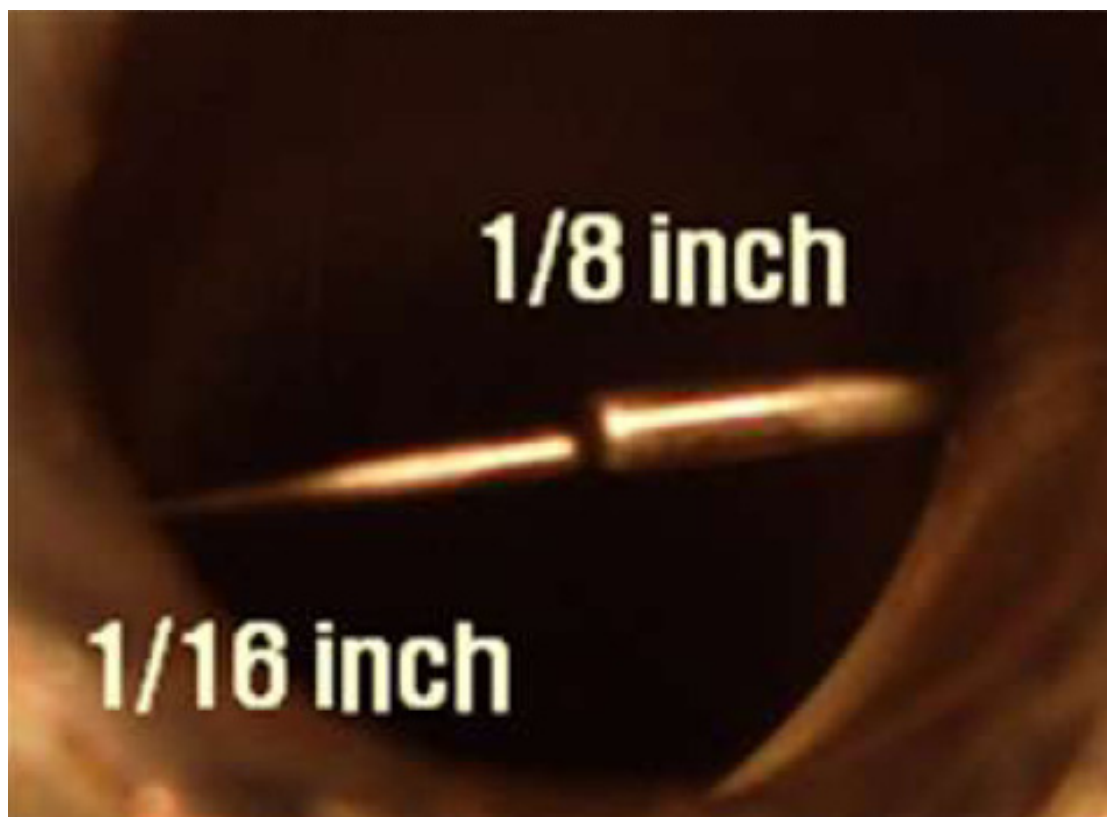

Figure 4: Two thermocouples in the pipe.

\section{Results and discussion}

Figure 5 shows the temperature histories in the tube at the inlet of the printed circuit heat exchanger in a small-scale gas loop. Since the inner surface of the channel was always lower than the gas temperature, the measure temperatures from a 1/16 inch were higher than those from a $1 / 8$ inch thermocouple.

Figure 6 shows the calculated convective and radiation heat transfer coefficients on the thermocouples from the experimental conditions at the measured temperature histories of Figure 5. Its mass flow rate range was about $1.0 \sim 1.5 \mathrm{~kg} / \mathrm{min}$. All the heat transfer coefficient increase with the gas temperature. In the high temperature region, the convective and radiation heat transfer coefficients on the sheath tube are large enough to neglect the conduction effect as the energy balance of equation (1). After $42000 \mathrm{sec}$, the dust from the heaters blocked the micro flow channels of the PCHE, so the mass flow rate was suddenly decreased. It was assumed that the mass flux on the sheath tube was the mean velocity. 


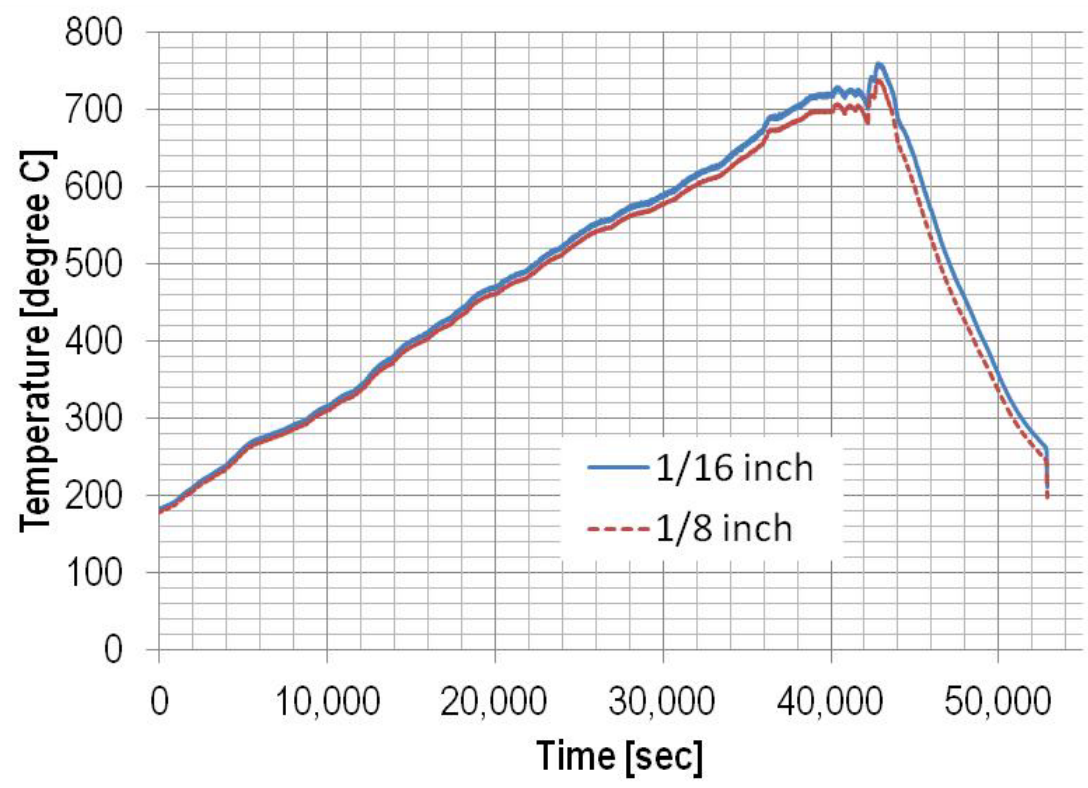

Figure 5: Temperature histories.

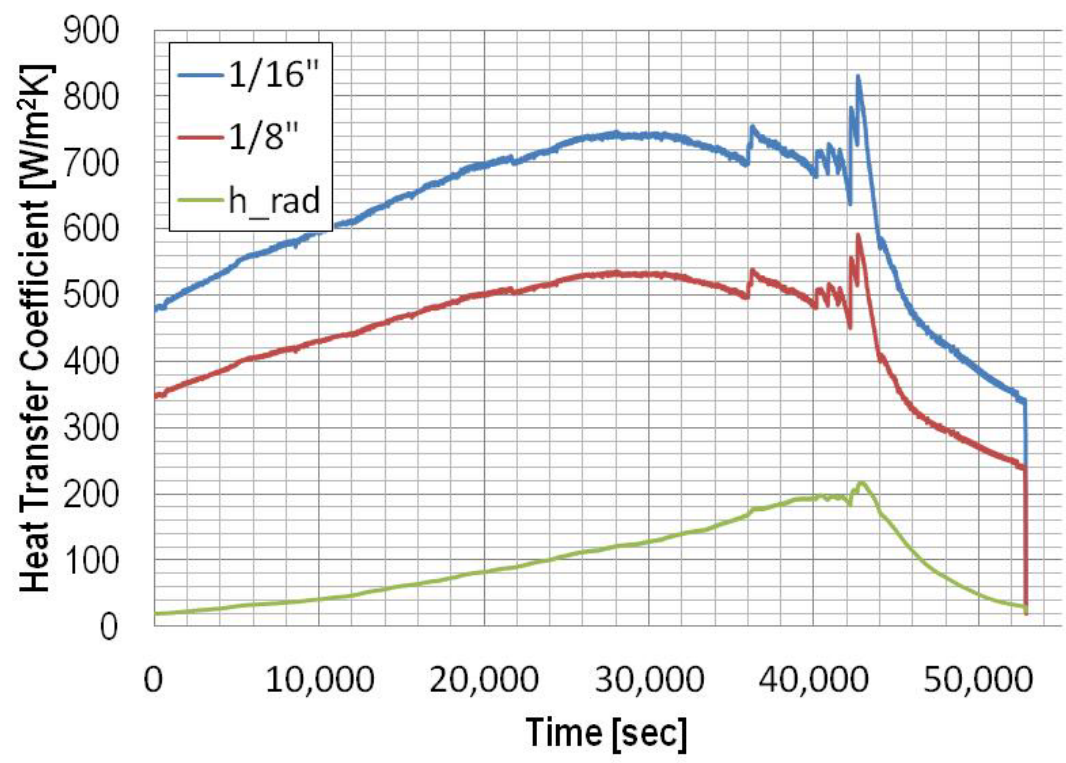

Figure 6: Calculated heat transfer coefficients. 
Figure 7 presents the RRE value history from the temperature histories in Figure 5. As shown in Figure 6, the radiation heat transfer coefficient between the thermocouples was increased with the measured gas temperature through thermocouples. Therefore, the RRE values at the high temperature region were higher than those at the low temperature region at the same mass flux condition.

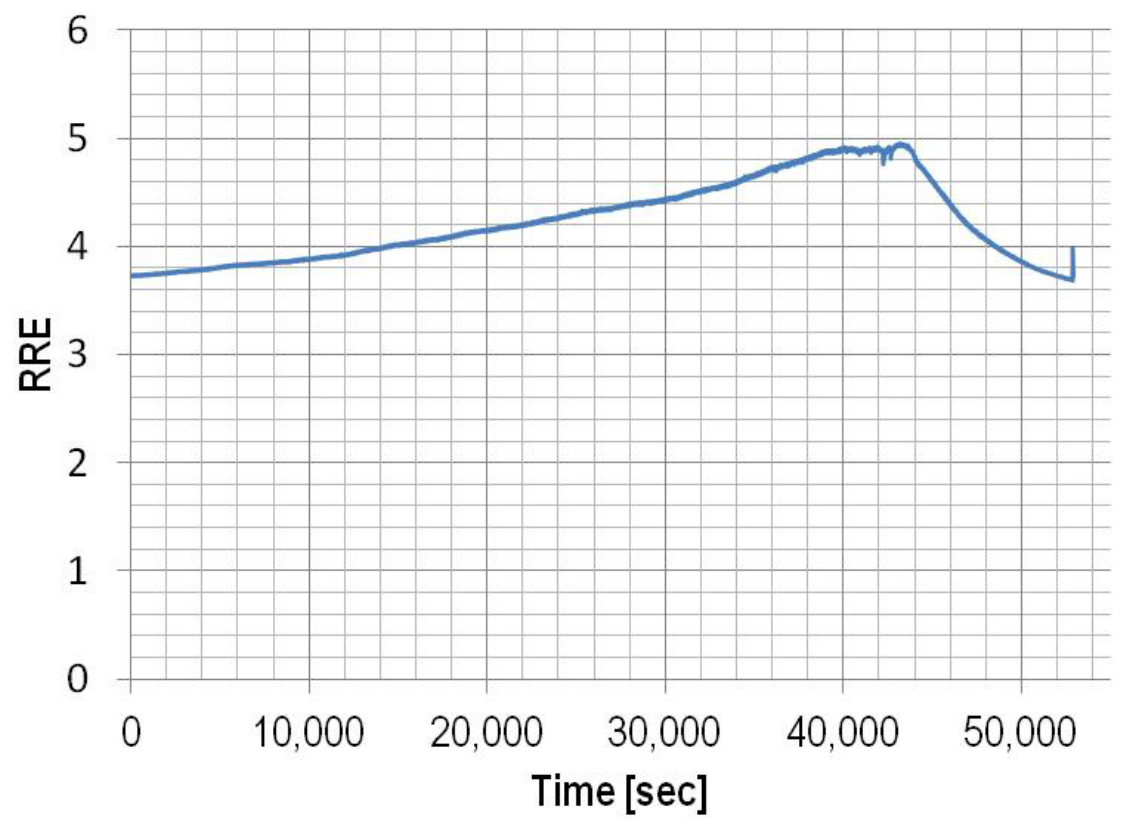

Figure 7: RRE value history.

Table 1 summarizes the experimental results of the mass velocity, the measured temperatures, the calculated gas temperature, and the effective radiation surroundings temperature including previous experimental results [9]. The radiation absorption effect is negligible in nitrogen, because the nonpolar symmetrical molecular structure of nitrogen results in little absorption of the thermal radiation except ultraviolet region. When it was assumed that the RRE corrected temperature was a true gas temperature, the effective radiation surroundings temperature could not be calculated from equation (1). It resulted from the overestimated radiation bias effect by the conduction heat loss in the sheath tubes. In the case of large mass flux conditions $(1.4 \sim 1.5 \mathrm{~kg} / \mathrm{min})$, the effective radiation surroundings temperature could not be calculated from equation (1), too. But the conduction loss was decreased in the case of the large mass flux conditions. Therefore the RRE method would have good applicability to the gas temperature measurement in the high temperature and mass flux condition under negligible conditions with the conductive dissipation through the sheath tubes. 
Table 1: $\quad$ Summary of RRE experimental results.

\begin{tabular}{|c|c|c|c|c|c|}
\hline $\begin{array}{c}\text { Mass V } \\
{[\mathrm{kg} / \mathrm{min}]}\end{array}$ & $\begin{array}{c}\mathrm{T}_{1} \\
{\left[{ }^{\circ} \mathrm{C}\right]}\end{array}$ & $\begin{array}{c}\mathrm{T}_{2} \\
{\left[{ }^{\circ} \mathrm{C}\right]}\end{array}$ & $\mathrm{RRE}$ & $\begin{array}{c}\mathrm{T}_{\mathrm{g}} \\
{\left[{ }^{\circ} \mathrm{C}\right]}\end{array}$ & $\begin{array}{c}\varepsilon \sigma \mathrm{T}_{\mathrm{s}}^{4} \\
{\left[\mathrm{~W} / \mathrm{m}^{2}\right]}\end{array}$ \\
\hline 0.76 & 160.8 & 146.5 & 3.61 & 198.0 & -18465.2 \\
\hline 0.81 & 247.2 & 227.9 & 3.64 & 297.8 & -28918.4 \\
\hline 0.76 & 360.2 & 328.1 & 3.63 & 444.7 & -51077.3 \\
\hline 0.81 & 474.4 & 430.2 & 3.67 & 592.3 & -79332.6 \\
\hline 0.71 & 552.1 & 493.6 & 3.69 & 709.6 & -101952.0 \\
\hline 1.42 & 191.4 & 189.1 & 3.73 & 198.0 & -2920.7 \\
\hline 1.51 & 288.1 & 284.7 & 3.85 & 297.8 & -4102.9 \\
\hline 1.54 & 430.3 & 425.5 & 4.08 & 444.6 & -3181.3 \\
\hline 1.50 & 567.3 & 559.1 & 4.38 & 592.3 & -4803.6 \\
\hline 1.34 & 689.0 & 675.3 & 4.75 & 732.0 & -7589.8 \\
\hline 1.40 & 750.3 & 731.7 & 4.90 & 810.2 & -16905.0 \\
\hline
\end{tabular}

The sheath tube conduction effect can be conservatively qualified as the conduction heat transfer at the very long fin as the following equations

$$
\begin{aligned}
& \mathrm{q}_{1}=\sqrt{\mathrm{hP}_{1} \mathrm{kA}_{\mathrm{c} 1}}\left(\mathrm{~T}_{1}-\mathrm{T}_{\text {room }}\right) \\
& \mathrm{q}_{2}=\sqrt{\mathrm{hP}_{2} \mathrm{kA}_{\mathrm{c} 2}}\left(\mathrm{~T}_{2}-\mathrm{T}_{\text {room }}\right)
\end{aligned}
$$

It was assumed that heat transfer coefficient on the sheath tube and the immersion length of the sheath tube was $40 \mathrm{~W} / \mathrm{m}^{2} \mathrm{~K}$ and $7 \mathrm{~mm}$, respectively. The true gas temperature is calculated from the energy balance including the conduction loss as the following equations.

$$
\begin{aligned}
& \mathrm{h}_{1}\left(\mathrm{~T}_{\mathrm{g}}-\mathrm{T}_{1}\right)=\varepsilon \sigma\left(\mathrm{T}_{1}^{4}-\mathrm{T}_{\mathrm{s}}^{4}\right)+\mathrm{q}_{1} /\left(0.5 \pi \mathrm{d}_{1}^{2}+\pi \mathrm{d}_{1} \mathrm{~L}\right) \\
& \mathrm{h}_{2}\left(\mathrm{~T}_{\mathrm{g}}-\mathrm{T}_{2}\right)=\varepsilon \sigma\left(\mathrm{T}_{2}^{4}-\mathrm{T}_{\mathrm{s}}^{4}\right)+\mathrm{q}_{2} /\left(0.5 \pi \mathrm{d}_{2}^{2}+\pi \mathrm{d}_{2} \mathrm{~L}\right)
\end{aligned}
$$

Since there are two unknowns in equations (7) and (8), true gas temperature can be solved as the following equation.

$$
\begin{aligned}
& \mathrm{T}_{\mathrm{g}}\left(\mathrm{h}_{1}-\mathrm{h}_{2}\right)=\varepsilon \sigma\left(\mathrm{T}_{1}^{4}-\mathrm{T}_{2}^{4}\right)+\mathrm{h}_{1} \mathrm{~T}_{1}-\mathrm{h}_{2} \mathrm{~T}_{2} \\
& +\mathrm{q}_{1} /\left(0.5 \pi \mathrm{d}_{1}^{2}+\pi \mathrm{d}_{1} \mathrm{~L}\right)-\mathrm{q}^{2} /\left(0.5 \pi \mathrm{d}_{2}^{2}+\pi \mathrm{d}_{2} \mathrm{~L}\right)
\end{aligned}
$$

Gas temperatures from equations (5) and (10) are the maximum gas temperature and the minimum gas temperature through the bias-correction, respectively. Figure 8 shows the measured gas temperatures from 1/16 inch and $1 / 8$ inch thermocouples and the calculated gas temperatures from equation (9) and (10). 


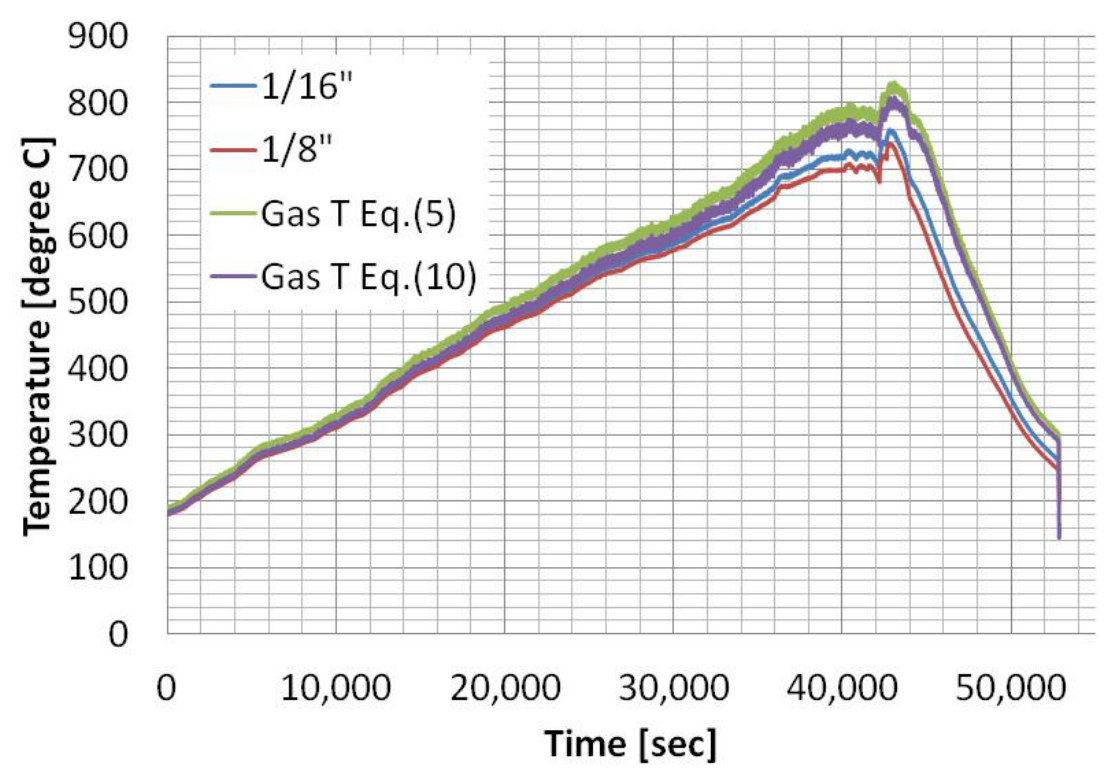

Figure 8: $\quad$ Histories of measured temperature and corrected temperature.

\section{Conclusion}

Experimental results show that the conduction loss through the sheath tube results in the overestimation of temperature difference between two thermocouples. But the sheath conduction effect at the large mass flux condition is larger than that at the small mass flux condition. An adequate immersion length and large mass velocity is necessary to obtain good applicability of RRE method. When the conduction effect is maximized by the infinite fin assumption, the corrected temperature with considering radiation and sheath conduction is the minimum value. The true gas temperature has a bounding value between the corrected temperature through RRE method and the corrected temperature with considering radiation and sheath conduction.

In the future, RRE method will be used in a very high temperature helium experimental loop. The helium loop has higher convective heat transfer coefficients and larger flow channels than the nitrogen loop in this paper. So, RRE method applicability in the helium loop will be better than that in the nitrogen loop.

\section{Acknowledgement}

This work was supported by Nuclear Research and Development Program of the Korea Science and Engineering Foundation grant funded by the Korean government (MEST). 


\section{Reference}

[1] Pitts, W. M., Braun, E., Peacock, R. D., Mitler, H.1 E.,Johnsson, E. L., Reneke, P. A., and Blevins, L. G., Temperature Uncertainties for BareBead and Aspirated Thermocouple Measurements in Fire Environments, Thermal Measurements: The Foundation of Fire Standards, ASTM STP 1427, L. A. Gritzo and N. J. Alvares, Eds., ASTM International, West Conshocken, PA, USA, 2002.

[2] Hennecke, D. K. and Sparrow, E. M., Local Heat Sink on a Convectively Cooled Surface-Application to Temperature Measurement Error, International Journal of Heat and Mass Transfer, Vol. 13, pp. 287-304. 1970.

[3] Luo, M., Effects of Radiation on Temperature Measurement in a Fire Environment, Journal of Fire Science, 15, pp. 443-461, 1997.

[4] Brohez, S., Delovsalle, C., and Marlair, G., A Two-Thermocouples Probe for Radiation Corrections of Measured Temperatures in Compartment Fires, Fire Safety Journal, 39, pp. 399-411, 2004.

[5] Men'shikov, V. I., Measurement of Gas-Flow Temperatures by Two Thermocouples, Journal of Engineering Physics, 31(5), pp. 300-306, 1977.

[6] Whitaker, S., Forced Convection Heat Transfer Correlations for Flow in Pipes, Past Flat Plates, Single Cylinders, Single Spheres, and for Flow in Paced Beds and Tube Bundles, AIChE Journal, 18, pp. 361-371, 1972.

[7] Kim, C. S., Hong, S. D., Kim, Y. W., Lee, W. J., and Chang, J. H., A Device for Measuring Gas Temperature with Radiation Interference Compensation and the Measurement Method, Submitted Patent in Republic of Korea, 10-2007-0123662, 2007.

[8] Kim, C. S., Hong, S. D., Kim, Y. W., and Chang, J. H., Apparatus for Measuring Gas Temperature, Submitted Patent in Republic of Korea, 102009-0135496, 2009.

[9] Kim, C. S., Seo, D. U., Yoo, T. H., and Hong, S. D., Performance Test of Nitrogen Loop with Hybrid Heat Exchanger for SO3 Decomposition of Nuclear Hydrogen Production, International Congress on Advances in Nuclear Power Plants, Paper 11454, Nice, France, 2011.

[10] Kim, C. S., Hong, S. D., Seo, D. U., and Kim, Y. W., Temperature Measurement with Radiation Correction for Very High Temperature Gas, Proceedings of the $14^{\text {th }}$ International Heat Transfer Conference, IHTC1423074, Washington, DC, 2010. 